\title{
Lipid composition and fluidity of the erythrocyte membrane in copper-deficient rats
}

\author{
BY K. M. ABU-SALAH \\ Department of Biochemistry, College of Science, King Saud University, PO Box 2455 , \\ Riyadh 11451, Saudi Arabia \\ AND A. A. AL-OTHMAN AND K. Y. LEI \\ Department of Nutrition and Food Science, University of Tucson, Arizona 85721, USA
}

(Received 15 April 1991 - Accepted 29 August 1991)

\begin{abstract}
The influence of dietary copper on lipid composition, phospholipid fatty acid and protein profiles and fluidity of the erythrocyte membranes of rats is reported. In general $\mathrm{Cu}$ deficiency in rats induced some changes in the phospholipid-fatty acid profile of erythrocyte membranes when compared with $\mathrm{Cu}$ adequate animals. Stearic (18:0) and docosadienoic (22:2n-3) acids contents, for example, were significantly increased $(P<0.001)$ while oleic $(18: 1 n-9)$ and linolenic $(18: 3 n-3)$ acid contents were significantly depressed $(P<0.001)$ as a result of $\mathrm{Cu}$ deficiency. Moreover the cholesterol : phospholipids molar ratio and the cholesterol (mol): membrane proteins (mg) ratio in $\mathrm{Cu}$-deficient rats were, to different degrees, significantly lower than in animals fed on $\mathrm{Cu}$-adequate diets. In addition, diets deficient in $\mathrm{Cu}$ led to a reduction in erythrocyte membrane fluidity $(P<0.001)$ as assessed by the intramolecular excimer fluorescence of 1,3-di(1-pyrenyl) propane. However, no significant alteration in the phospholipid : protein ratio was observed as a result of differences in dietary treatment. The pattern of erythrocyte membrane proteins obtained with sodium dodecyl sulphate-polyacrylamide gel electrophoresis did not seem to be influenced by $\mathrm{Cu}$-deficient diets.
\end{abstract}

Cu deficiency: Erythrocyte membranes: Membrane lipids: Membrane fluidity: Rat

Hypercholesterolaemia associated with copper deficiency has been observed by numerous investigators, mostly in rats but also in other species including humans (for a recent review, see Lei, 1990). Lei $(1977,1978)$ suggested that a shift of cholesterol from the liver pool to the plasma pool appeared to be responsible. Shao \& Lei (1980) demonstrated that cholesteryl ester, newly synthesized from $\left[2-{ }^{14} \mathrm{C}\right]$ mevalonate, cleared the liver faster in $\mathrm{Cu}$ deficient rats. In addition, a 2 -fold increase in fatty acid synthesis from $\left[{ }^{14} \mathrm{C}\right]$ acetate was observed in liver slices derived from $\mathrm{Cu}$-deficient rats (Lei, 1977). Furthermore, an increase in hepatic cholesterol synthesis was indicated by a 2-fold increase in hepatic 3-hydroxy-3methylglutaryl-CoA reductase (EC 1.1.1.88) activity (Yount et al. 1990) and by findings on in vivo cholesterol synthesis (Yount et al. 1991). Thus, the increased capacity of hepatic fatty acid and cholesterol synthesis and enhanced clearance of cholesteryl ester both may have contributed to the hypercholesterolaemia and hyperlipoproteinaemia observed in Cu-deficient rats (Croswell \& Lei, 1985; Lei et al. 1989). Recently, Al-Othman et al. (1990), expressed plasma lipoprotein as the amount present in the vascular pool corrected for body-weight. The plasma pool size of protein, triacylglycerols (TG) and phospholipids (PL) and cholesterol of low-density lipoprotein (LDL) and high-density lipoprotein (HDL) were increased 2 -fold or more by $\mathrm{Cu}$ deficiency. As for very-low-density lipoprotein (VLDL), a 6 -fold increase in TG, a $36 \%$ reduction in cholesterol, and no change in PL and protein 
pool sizes were observed in $\mathrm{Cu}$-deficient rats. In addition, changes in HDL-PL fatty acid composition were represented by a $61 \%$ increase in stearate and reductions of $44 \%$ and $97 \%$ in oleate and linolenate respectively as a result of $\mathrm{Cu}$ deficiency. These alterations may exert a profound influence on the lipid composition of many important cellular membranes, such as the erythrocyte membrane, which are in constant contact with plasma lipoproteins. Alterations in membrane lipid composition such as the cholesterol content of the membrane (Ladbrooke et al. 1968) and length and degree of unsaturation of phospholipid (Schwarz et al. 1984) resulted in modifications in the membrane fluidity. In view of the changes in lipid metabolism induced by $\mathrm{Cu}$ deficiency, the influence of PL acyl groups and cholesterol on membrane fluidity and the importance of membrane fluidity on membrane activities (Abu-Salah et al. 1988; Abu-Salah, 1991) and cellular functions (Spector \& Yorek, 1985), the present study was performed to determine the influence of Cu status on lipid composition, PL fatty acid profile, protein profile and fluidity of the erythrocyte membrane.

\section{EXPERIMENTAL}

\section{Materials}

1,3-di(1-pyrenyl)propane (DPP) was purchased from Molecular Probes, Inc, 4849 Pitchford Ave, Eugene, OR 97402. Dextran T500 was obtained from Pharmacia Fine Chemicals AB, Box 175, S-75104, Uppsala 1, Sweden. The $\mathrm{Cu}$ reference standard was provided by Fisher Scientific Co., Los Angeles, CA. Standard fatty acids were obtained from Supelco Inc., Bellefonte, PA. All other reagents were at least Analytical grade and were obtained from Sigma Chemical Co., St Louis, MO 63178.

\section{Methods}

Animals and diets. Weanling male Sprague-Dawley rats were housed individually in suspended stainless-steel wire cages in a laboratory maintained at $22^{\circ}$ with a $12 \mathrm{~h}$ light-dark cycle. Rats were randomly allocated to the dietary treatments $(\mathrm{Cu}$-deficient and $\mathrm{Cu}-$ adequate). The $\mathrm{Cu}$-deficient diet was prepared according to the specifications of American Institute of Nutrition (1977), except that the Cu supplement was omitted from the mineral mix. The diet contained $0.7 \mathrm{mg} \mathrm{Cu} / \mathrm{kg}$ diet as determined by atomic absorption spectrophotometry (Hitachi Ltd, 1980) using the certified reference standards of Fisher Scientific Co. Copper carbonate was added to the basal diet to achieve a level of $8.0 \mathrm{mg}$ $\mathrm{Cu} / \mathrm{kg}$. Diet and distilled demineralized water were provided ad lib. The dietary treatment continued for 8 weeks before animals were exsanguinated.

\section{Preparation of erythrocyte ghosts (membrane)}

In a typical experiment, five male rats weighing $700-1000 \mathrm{~g}$ from each group of $\mathrm{Cu}-$ adequate and $\mathrm{Cu}$-deficient animals were fasted for $12 \mathrm{~h}$ and exsanguinated under diethyl ether anaesthesia. Blood was withdrawn directly from the heart, by cardiac puncture after thoraco-abdominal incision, into syringes containing EDTA. Collected blood was centrifuged at $1000 \mathrm{~g}$ for $30 \mathrm{~min}$ at $4^{\circ}$ in tubes containing EDTA $(1 \mathrm{mg} / \mathrm{ml})$. Plasma and the buffy coats were removed and the cells were resuspended in $0 \cdot 1 \mathrm{M}$-Tris-hydrochloric acid buffer $\mathrm{pH} 7 \cdot 6$, then centrifuged again as described previously. The erythrocytes thus obtained were washed twice after removal of the buffy coats. Erythrocyte ghosts were prepared as described by Hanahan \& Ekholm, 1974. Briefly, washed erythrocytes obtained from $\mathrm{Cu}$-adequate and $\mathrm{Cu}$-deficient animals were suspended in about seven times

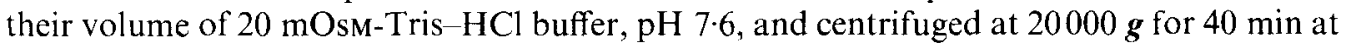
$4^{\circ}$. The supernatant fraction was aspirated carefully and with minimal contamination from 
the small fibrin-like skin, which contained the ghosts, at the bottom of the tube. Membranes were washed thrice more as described previously.

Protein estimation. Protein concentrations of prepared ghosts were measured, after solubilizing the membranes in sodium dodecylsulphate $(20 \mathrm{~g} / 1$; SDS), using the manual ninhydrin method (Hirs, 1967). Bovine serum albumin in SDS was used as a standard. Plasma membranes were stored frozen at $-20^{\circ}$ in $11.0 \mathrm{~mm}$-Tris buffer, $\mathrm{pH} 7.6$ at $4 \mathrm{mg}$ protein $/ \mathrm{ml}$ buffer.

$S D S$-polyacrylamide gel electrophoresis (SDS-PAGE). Membranes obtained from Cuadequate and $\mathrm{Cu}$-deficient rats were dissolved in SDS in $11.0 \mathrm{~mm}-\mathrm{Tris}-\mathrm{HCl}, \mathrm{pH} \mathrm{7.7}$, and incubated with or without $0.5 \mathrm{M}$-dithiothreitol for $40 \mathrm{~min}$ at $37^{\circ}$. Samples thus prepared were subjected to electrophoresis by the method of Weber \& Osborn (1969) as described by Abu-Salah (1978). Samples of not less than $100 \mu \mathrm{g}$ membrane proteins were applied at $\mathrm{pH} 8.5$ to $7.5 \%$ discontinuous polyacrylamide gels with $10 \mathrm{~g}$ methylenebisacrylamide/1-1 g SDS/1. Bromophenol blue in glycerol $(100 \mathrm{ml} / 1)$ was used as a tracking dye. Gels were pre-run for $1 \mathrm{~h}$ at $1 \mathrm{~mA} /$ gel then for $4 \mathrm{~h}$ at $7 \mathrm{~mA} / \mathrm{gel}$. Gels were stained in Coomassie brilliant blue R250 $(2.5 \mathrm{~g} / 1)$ in methanol $(400 \mathrm{ml} / \mathrm{l})$ in acetic acid $(75 \mathrm{~g} / 1)$ and the excess dye was washed out with methanol $(400 \mathrm{ml} / \mathrm{l})$ in acetic acid $(75 \mathrm{~g} / \mathrm{l})$. Gels were scanned using a LKB 2202 UltroScan laser densitometer equipped with a helium-neon laser as a light source.

\section{Lipid extraction and analyses}

Total lipids were extracted from ghosts with a chloroform-methanol mixture $(2: 1, \mathrm{v} / \mathrm{v})$ as described by Folch et al. (1957). Cholesterol and total PL contents were determined by the methods of DeHoff et al. (1978) and Fiske \& Subbarow (1925) respectively. PL were separated by thin-layer chromatography developed with $n$-hexane-diethyl ether-acetic acid-methanol (90:20:2:3, by vol; Brown \& Johnston, 1962). Base-catalysed transesterification (Morrison \& Smith, 1960) was performed with sodium methoxide (Tahin et al. 1981) to convert fatty acids of PL to their fatty acid methyl esters, which were measured using a Shimadzu gas-liquid chromatograph, (Model 8A, equipped with a Supelco Wax 10 wide-pore capillary column $30 \mathrm{~mm} \times 0.75 \mathrm{~mm}$ ). Measurements were performed at temperatures of $280^{\circ}$ and $220^{\circ}$ for the injection and column respectively and at nitrogen carrier gas pressure of $0.9 \mathrm{~kg} / \mathrm{cm}^{2}$. Peaks were identified by comparison of retention times with those of standard fatty acids, and integrated using a Hewlett-Packard 3390 A Integrator.

Excimer fluorescence. The method used was essentially that of Storch \& Schachter (1984), modified for rat hepatocyte plasma membrane.

A stock solution of $0.15 \mathrm{~mm}-1,3 \mathrm{di}(1$-pyrenyl)propane (DPP) was freshly prepared in absolute alcohol by stirring in the dark, in a hot water-bath, for $45 \mathrm{~min}$. Freshly-thawed membranes were resuspended by sonication for $10 \mathrm{~s}$ using Fisher Sonic Dismembrators Model 150 (Artek Systems Corporation), in $400 \mu \mathrm{l}$ Tris-buffered saline (TBS; $5 \mathrm{~mm}$ Tris-146 mM-sodium chloride-4 mm-potassium chloride, $\mathrm{pH} 7 \cdot 4$ ). The incubation mixture containing ( $3.75 \mu \mathrm{M} \mathrm{DPP} / \mathrm{mg}$ protein) was prewarmed to $37^{\circ}$ and vortexed vigorously for $20 \mathrm{~s}$, and then incubated in the dark at $37^{\circ}$ for $1.5 \mathrm{~h}$ with constant shaking. To each sample, $3 \mathrm{ml}$ deoxygenated TBS (evacuated and flushed with highly purified $\mathrm{N}_{2}$ for $30 \mathrm{~min}$ ) was added. The diluted mixture was layered to the top of $2 \mathrm{ml}$ Dextran T500 $(200 \mathrm{~g} / \mathrm{l}$; Pharmacia) to separate the insoluble aggregate of DPP from the suspension. The upper phase containing the membrane was removed after it had stood for $10 \mathrm{~min}$. Membranes were pelleted then washed twice, after resuspending them by sonication in $5 \mathrm{ml}$ deoxygenated TBS, by centrifugation at $45000 \mathrm{~g}$ for $25 \mathrm{~min}$ at $20^{\circ}$. The washed pellet was suspended in $4 \mathrm{ml}$ deoxygenated TBS and allowed to stand at room temperature for $3 \mathrm{~h}$. 


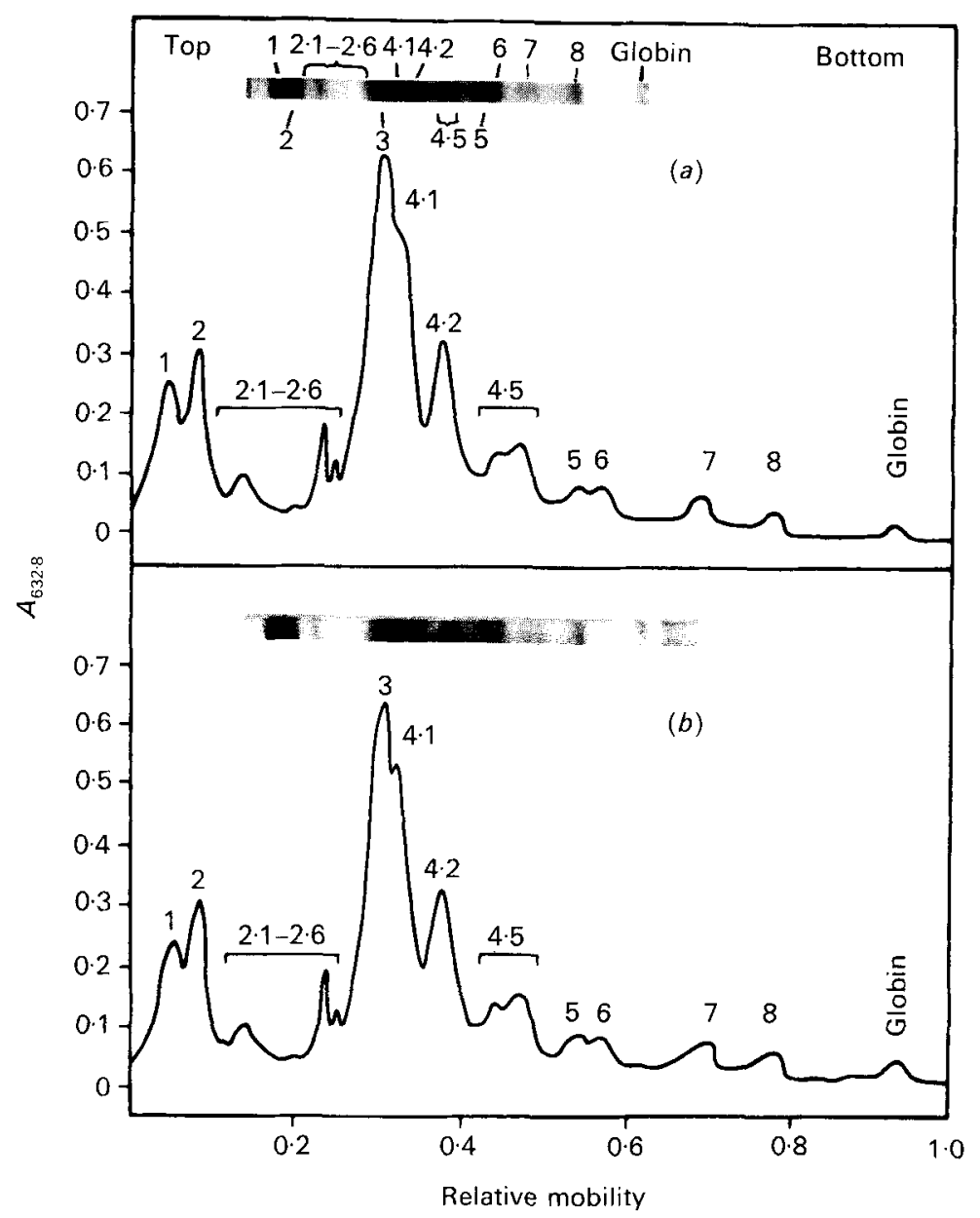

Fig. 1. Electrophoresis patterns and densitometric scans of Coomassie Blue-stained gels showing typical protein profiles of erythrocyte membranes from rats fed on $(a)$ copper-adequate and $(b) \mathrm{Cu}$-deficient diets. Gels were scanned using a LKB 2202 UltroScan laser densitometer at a wavelength of $632.8 \mathrm{~nm}$, and absorbance of 1.0 , a speed of $60 \mathrm{~mm} / \mathrm{min}$, a peak width of 0.2 and a reject area of $10^{6}$. The nomenclature used is based on that suggested by Steck (1974).

Fluorescence emission spectra were recorded at $20^{\circ}$ with a Perkin-Elmer $650-15$ fluorescence spectrophotometer at a sensitivity of 0.1 and at a time constant of $0 \cdot 3$. An excitation wavelength of $345 \mathrm{~nm}$ was employed. Excimer and monomer fluorescence peak intensities were monitored at 485 and $396 \mathrm{~nm}$ respectively. Fluorescence intensities were corrected for membranes carried under identical conditions without DPP and for the probe added to TBS alone.

\section{RESULTS}

The criteria of $\mathrm{Cu}$ deficiency such as the significant depression in weight gain, increased heart:body-weight ratio and depleted hepatic $\mathrm{Cu}$ stores were all clearly established compared with rats fed on Cu-adequate diets as described by Allen et al. (1982).

SDS-PAGE patterns demonstrated no difference in the membrane-protein profiles from $\mathrm{Cu}$-adequate and $\mathrm{Cu}$-deficient rats (Fig. 1). Nevertheless, the fatty acid profile of membrane PL derived from erythrocytes was influenced by dietary treatment. Among the individual 
Table 1. Fatty acid composition of erythrocyte membranes of copper-adequate and $\mathrm{Cu}$ deficient rats*

(Mean values with their standard errors)

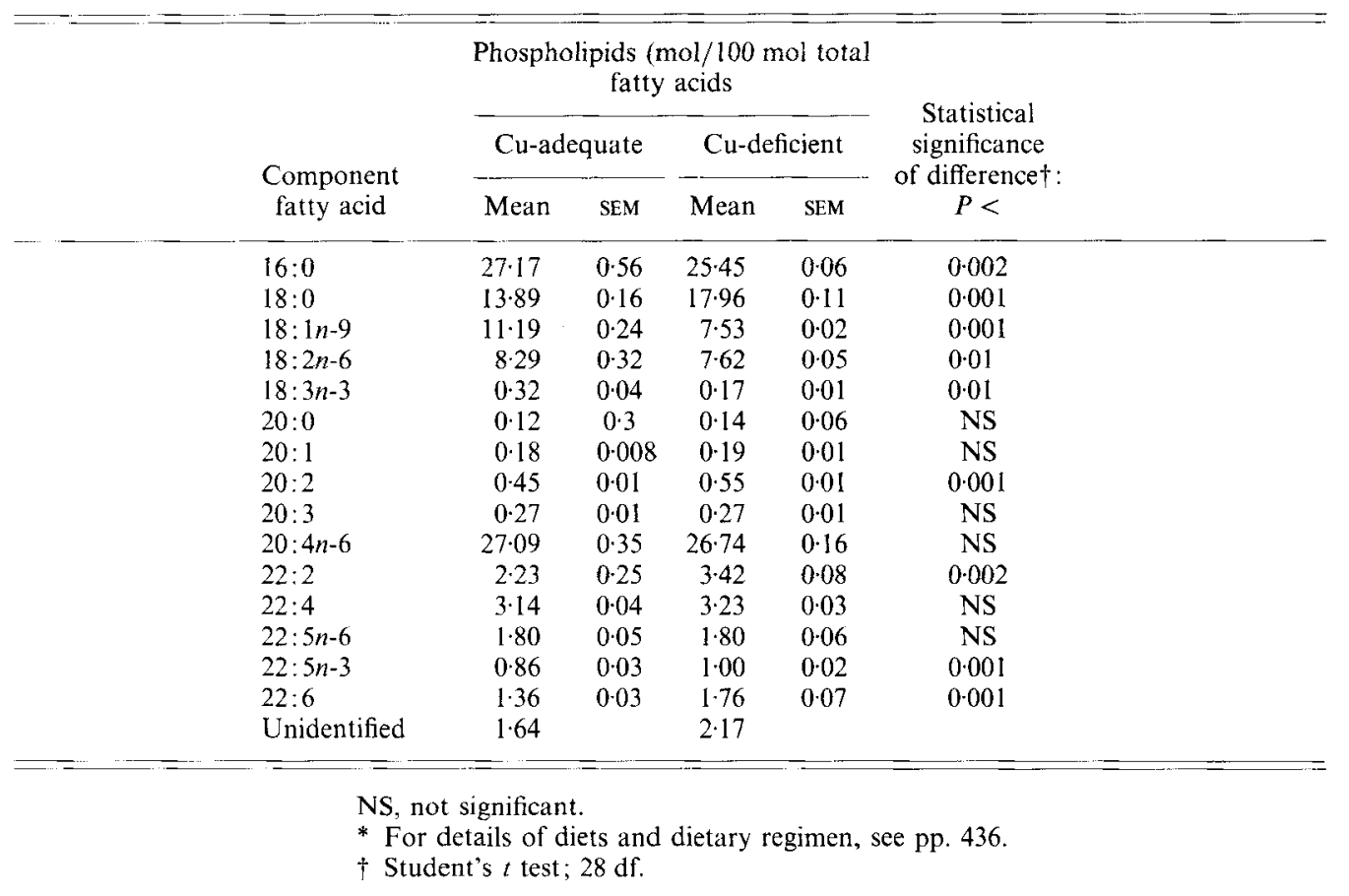

fatty acids, significant elevations in stearic $(18: 0,29 \cdot 3 \%)$, docosahexaenoic $(22: 6 n-3$, $29.4 \%)$ and docosadienoic $(22: 2 n-3,53.4 \%)$ acids were observed in $\mathrm{Cu}$-deficient rats. On the other hand, reductions in oleic $(18: 1 n-9,32.7 \%)$ and linolenic $(18: 3 n-3,46.9 \%)$ acids were observed in Cu-deficient treatment (Table 1). Membrane fluidity was assessed by measurement of the fluorescence of excited complexes (excimers) of an intramolecular excimer-forming fluorophore, DPP. DPP has been used to monitor short-range lateral diffusion of pyrene substituents in the erythrocyte membrane (Zacharaisse et al. 1982). The short-range lateral diffusion in plasma membranes was evaluated by the use of excimer: monomer fluorescence intensity ratio of DPP. The reduction in this ratio observed in the erythrocyte membranes of $\mathrm{Cu}$-deficient rats indicated a decreased fluidity (Table 2).

In order to evaluate the degree of fatty acid unsaturation in the PL of the erythrocyte membranes of $\mathrm{Cu}$-adequate and $\mathrm{Cu}$-deficient animals, the double-bond index was derived from the sum of product of the proportion of each fatty acid multiplied by the number of double bonds in that acid. When the index was calculated up to and including arachidonic acid $(20: 4 n-6)$ as described by Storch \& Schachter (1984), a significant reduction was observed (Table 2) for membrane PL fatty acids from $\mathrm{Cu}$-deficient compared with $\mathrm{Cu}$ adequate rats. However, when the fatty acids up to 22:6 were used in the calculation the double-bond index was not significantly altered. On the other hand, a significant decrease $(P<0.001)$ in the unsaturated:saturated PL fatty acids was observed in Cu-deficient compared with $\mathrm{Cu}$-adequate rats (Table 2). Moreover, the oleic:stearic PL fatty acid ratio was significantly depressed as a result of $\mathrm{Cu}$ deficiency. These two fatty acids together 
Table 2. Fluidity variables and lipid composition of erythrocyte membranes in copperadequate and $\mathrm{Cu}$-deficient rats*

(Mean values with their standard errors)

\begin{tabular}{|c|c|c|c|c|c|}
\hline \multirow[b]{2}{*}{ Variable } & \multicolumn{2}{|c|}{ Cu-adequate } & \multicolumn{2}{|c|}{ Cu-deficient } & \multirow{2}{*}{$\begin{array}{c}\text { Statistical } \\
\text { significance } \\
\text { of differencet: } \\
P<\end{array}$} \\
\hline & Mean & SEM & Mean & SEM & \\
\hline Excimer : monomer fluorescence intensity $\downarrow$ & $0 \cdot 335$ & $0 \cdot 003$ & $0 \cdot 274$ & $0 \cdot 011$ & $0 \cdot 001$ \\
\hline $\begin{array}{l}\text { Double-bond index up to and including arachidonic acid } \\
(20: 4 n-6) \S\end{array}$ & $1 \cdot 367$ & 0.017 & $1 \cdot 294$ & $0 \cdot 007$ & $0 \cdot 001$ \\
\hline Double bond index for all phospholipid-fatty acids $\S$ & 1.746 & 0.024 & $1 \cdot 728$ & 0.005 & NS \\
\hline Ratio of $18: 1$ to $18: 0$ phospholipids-fatty acids & 0.806 & 0.007 & 0.419 & 0.0002 & 0.001 \\
\hline $\begin{array}{l}\text { Percentage unsaturated : percentage saturated } \\
\text { phospholipid-fatty acids }\end{array}$ & $1 \cdot 389$ & 0.026 & $1 \cdot 246$ & 0.008 & 0.001 \\
\hline Cholesterol ( $\mu \mathrm{mol} / \mathrm{mg}$ membrane protein) & 0.480 & $0 \cdot 013$ & $0 \cdot 457$ & $0 \cdot 003$ & $0 \cdot 1$ \\
\hline Phospholipid ( $/ \mathrm{mol} / \mathrm{mg}$ membrane protein) & 0.520 & $0 \cdot 013$ & 0.526 & $0 \cdot 007$ & NS \\
\hline Cholesterol:phospholipid molar ratio & 0.923 & 0.005 & $0 \cdot 870$ & 0.008 & 0.01 \\
\hline
\end{tabular}

NS, not significant.

* For details of diets and dietary regimen, see pp. 436.

$\dagger$ Student's $t$ test; $28 \mathrm{df}$.

$+22 \mathrm{df}$.

$\S$ The nature (no. of double bonds, if any) of the unidentified fatty acids was unknown, thus, they were excluded when calculating the double bond index.

constitute a significant proportion of PL fatty acids (approximately $25 \mathrm{~mol} / 100 \mathrm{~mol}$ ) (Table 1) in the erythrocyte membrane.

In the light of the important influence of the cholesterol:PL ratio on the fluidity of PL vesicles and biomembranes (Ladbrooke et al. 1968; Cooper et al. 1978; Giraud et al. 1981), the effect of $\mathrm{Cu}$ deficiency on the ratio was examined in the present study. The cholesterol: PL molar ratio was significantly decreased $(P<0.01$, Student's $t$ test) in rats fed on Cu-deficient diets (Table 2). Nevertheless, the cholesterol (mol): protein (mg) ratio was slightly lower in $\mathrm{Cu}$-deficient rats $(P<0 \cdot 1)$ and the $\mathrm{PL}$ : protein ratio did not seem to be affected at all by $\mathrm{Cu}$ deficiency.

\section{DISCUSSION}

Alterations in the PL fatty acid profile of the erythrocyte membrane are similar to those reported for HDL derived from Cu-deficient rats (Al-Othman et al. 1990). However, the magnitude of changes in the PL fatty acid profile of HDL appeared to be greater than that of the erythrocyte membrane, in terms of the increase in 18:0 and reductions in $18: 3$. These similarities may have resulted from equilibrium exchange of PL fatty acids, aided by the PL ester transfer protein and to a lesser extent by the cholesterol transfer protein between the erythrocytes and HDL (Tall, 1986).

Since the present study is the first to demonstrate the detailed PL fatty acid composition of the erythrocyte membrane in rats and the pattern by which it is influenced by $\mathrm{Cu}$ deficiency, the results are compared with a previous study (Lei et al. 1988) on the effect of $\mathrm{Cu}$ deficiency on rats hepatic plasma membranes. The present study revealed a different PL fatty acid profile and different trends in the changes in the relative proportions of erythrocyte membrane fatty acids in $\mathrm{Cu}$-deficient rats compared with hepatic plasma membrane. Whereas $\mathrm{Cu}$-deficient dietary treatments resulted in a reduction in the ratio of 
18:0 to $18: 1$ fatty acids in the erythrocyte membrane, the ratio remained unchanged in hepatic plasma membranes. Moreover, while the proportion of arachidonic acid $(20: 4 n-6)$ was not affected at all in the PL of the erythrocyte membrane, it was reduced markedly in the PL of the hepatic membrane. The marked reduction in arachidonic acid in the $\mathrm{Cu}-$ deficient hepatic plasma membrane may have resulted from an enhanced turnover of this PL fatty acid. An increased release of $20: 4$ by phospholipase $A_{2}$ (EC 3.1.1.4) to form eicosanoids, or an increased removal of oxidized 20:4 in the detoxification of PL peroxides (Van Kuijk et al. 1987), are possible explanations. Alternatively, the supply of $20: 4$ for hepatic plasma membrane PL formation and regeneration may be depressed by $\mathrm{Cu}$ deficiency resulting in the reduction in $20: 4$.

The reduction in excimer:monomer fluorescence intensity ratio of DPP suggests a decreased lateral diffusion in the erythrocyte membranes of $\mathrm{Cu}$-deficient rats. The significant reduction in the double bond index calculated up to and including arachidonic acid could be considered as a contributing factor in the observed decrease in membrane lateral fluidity. Nevertheless, the value of the double-bond index obtained when the fatty acids up to 22:6 were used showed no significant difference in the degree of unsaturation of PL fatty acids from $\mathrm{Cu}$-deficient compared with $\mathrm{Cu}$-adequate rats. Thus, the index may not be a good indicator of the degree of unsaturation when small amounts of fatty acids greater than 20:4 are included in the calculations. On the other hand, an increase $(4 \%$ of the total PL fatty acid composition) in the saturated stearic acid accompanied by a large decrease $(32.7 \%)$ in the unsaturated oleic acid and consequently a decrease $(52 \%)$ in the ratio of $18: 1$ to $18: 0$ may be a major contributing factor in the observed reduction in membrane fluidity in $\mathrm{Cu}$-deficient rats. The significant decrease in the ratio of $18: 1$ to 18:0 may be explained, at least in part, by a possible decrease in the activity of 9-desaturase (Wahle \& Davies, 1975) which normally requires $\mathrm{Cu}$ for its activity. Moreover, further evaluation of the degree of unsaturation revealed a significant reduction in the total unsaturated : total saturated fatty acid ratio in $\mathrm{Cu}$-deficient rats, thus, providing support for the reduction in the proportion of unsaturated fatty acids and the ratio of $18: 1$ to 18:0 fatty acids, which indicated a decrease in unsaturation. The reduced cholesterol (mol): PL ( $\mathrm{mg}$ ) ratio is a strong indication of a decrease in the molar proportions of cholesterol in the erythrocyte membranes in rats fed on $\mathrm{Cu}$-deficient diets. The reduced amount of cholesterol is expected to result in an increase in the disordering effect and hence in the fluidity of the membrane (Ladbrooke \& Chapman, 1969; Cooper et al. 1978; Giraud et al. 1981), provided the PL fatty acid composition is kept unchanged. Nevertheless, the reduction in the cholesterol:PL molar ratio in $\mathrm{Cu}$-deficient rats was accompanied by a decrease in the degree of unsaturation of the fatty acids and in a significant increase in some saturated fatty acids, such as stearic acid. Therefore, the observed decrease in the fluidity of erythrocyte membrane could be accounted for, at least in part, on the basis of the combined effect cholesterol has on restricting the motion of unsaturated fatty acids and preventing saturated chains from crystallizing (Ladbrooke et al. 1968). The PL:protein ratio as a whole did not seem to have any influence on modulating the fluidity of the erythrocyte membranes as the ratio was not affected by different dietary treatments.

The small but significant reduction in cholesterol content observed in the erythrocyte membranes of $\mathrm{Cu}$-deficient rats could be due to an impaired delivery of cholesterol to developing stem cells of bone marrow or a small efflux of cholesterol from the erythrocytes. This occurs despite the increases in both total plasma cholesterol (Lei, 1977, 1990) and HDL-cholesterol (Yount et al. 1990) in Cu-deficient rats. Alternatively, the decreased cholesterol content of erythrocyte membranes may have resulted from an impaired incorporation of cholesterol in the membranes of developing stem cells as a result of the observed alteration in their PL fatty acid composition. 
SDS-PAGE membrane protein profile did not seem to be altered by Cu-deficient diets. This finding is not in agreement with that obtained by Johnson \& Kramer (1987) who reported a significant increase in the amount of a $170000 \mathrm{Da}$ protein in the membrane of erythrocytes derived from rats fed on Cu-deficient diets. The differences in SDS-PAGE protein profiles obtained from both studies could be due to differences in dietary composition used.

The results of the present study demonstrate that the lipid composition and fluidity of erythrocyte membranes are responsive to the animals' $\mathrm{Cu}$ status and suggest that other cellular functions such as the transport of ions and nutrients dependent on optimal membrane fluidity may also be altered.

The authors thank H. A. Gambo and A. A. Awad for technical assistance.

\section{REFERENCES}

Abu-Salah, K. M. (1978). Studies on the myelin membrane of mammalian nerve cells. Ph.D. Thesis, University of Leeds.

Abu-Salah, K. M. (1991). Perturbation of the fluidity of the erythrocyte membrane with ionophoric antibiotics and lipophilic anaesthetics. Biochemical Pharmacology 42, 1947-195I.

Abu-Salah, K. M., Sedrani, S. H., Tobia, A. S. \& Gambo, H. A. (1988). Influence of amphotericin B on the transport of phosphate, sulphate and potassium ions across the human erythrocyte membrane. Acta Haematologica 79, 77-80.

Allen, D. K., Hassel, C. A. \& Lei, K. Y. (1982). Function of pituitary thyroid axis in copper-deficient rats. Journal of Nutrition 112, 2043-2046.

Al-Othman, A. A., Rosenstein, F. \& Lei, K. Y. (1990). Alterations in plasma pool size of lipoprotein components and fatty acid composition of high density lipoprotein phospholipids in copper-deficient rats. FASEB Journal 4, A393.

American Institute of Nutrition (1977). Report of the AIN ad hoc committee on standards for nutritional studies. Journal of Nutrition 107, 1346-1348.

Brown, J. L. \& Johnston, J. M. (1962). Radioassay of lipid components separated by thin layer chromatography. Journal of Lipid Research 3, 480481.

Cooper, R. A., Leslie, M. H., Fischkoff, S., Shinitzky, S. \& Shattil, S. J. (1978). Factors influencing the lipid composition and fluidity of red cell membranes in vitro: Production of red cell possessing more than two cholesterols per phospholipid. Biochemistry 17, 327-332.

Croswell, S. \& Lei, K. Y. (1985). Effect of copper deficiency on the apolipoprotein E-rich high density lipoproteins in rats. Journal of Nutrition 115, 473-482.

DeHoff, J. L., Davidson, L. M. \& Kritchevsky, D. (1978). An enzymatic assay for determining free and total cholesterol in tissue. Clinical Chemistry 24, 433-435.

Fiske, C. H. \& Subbarow, Y. (1925). The colorimetric determination of phosphorus. Journal of Biological Chemistry 66, 375-402.

Folch, J., Lees, M. \& Sloan Stanley, G. H. (1957). A simple method for the isolation and purification of total lipides from animal tissue. Journal of Biological Chemistry 226, 497-509.

Giraud, F., Claret, M., Bruckdorfer, R. \& Chailley, B. (1981). The effects of membrane lipid order and cholesterol on the internal and external cation sites of the $\mathrm{Na}^{+}-\mathrm{K}^{+}$pump in erythrocytes. Biochimica et Biophysica Acta 647, 249-259.

Hanahan, D. J. \& Ekholm, H. E. (1974). The preparation of red cell ghosts (membranes). In Methods in Enzymology, vol. 31, pp. 168-170, [S. Fleischer and L. Packer, editors]. New York: Academic Press.

Hirs, C. H. W. (editor) (1967). Detection of peptides by chemical methods. In Methods in Enzymology, vol. 11, pp. 325-329. New York: Academic Press.

Hitachi Ltd (1980). Instruction Manual, Model 180 70 Polarized Zeeman Atomic Absorption Spectrophotometer. Mountain View, CA: Sangyo America.

Johnson, W. T. \& Kramer, T. R. (1987). Effect of copper deficiency on erythrocyte membrane proteins of rats. Journal of Nutrition 117, $1085-1090$.

Ladbrooke, B. D. \& Chapman, D. (1969). Thermal analysis of lipids, proteins and biological membranes. Chemistry and Physics of Lipids 3, 304 356.

Ladbrooke, T. J., Jenkinson, T. J., Kamat, V. B. \& Chapman, D. (1968). Physical studies of myelin. I. Thermal analysis. Biochimica et Biophysica Acta 164, 101-109.

Lei, L. Y. (1977). Cholesterol metabolism in copper-deficient rats. Nutrition Reports International 15, 597605.

Lei, K. Y. (1978). Oxidation, excretion and tissue distribution of $\left[26-{ }^{14} \mathrm{C}\right]$ cholesterol in copper deficient rats. Journal of Nutrition 108, 232-237. 
Lei, K. Y. (1990). Plasma cholesterol response in copper deficiency. In Role of Copper in Lipid Metabolism, pp. 1-57 [K. Y. Lei and T. P. Carr, editors]. Boca Raton, FL: CRC Press.

Lei, K. Y., Hendriks, H. F. J., Brouwer, A., Bock, I., DeRuiter, C. S. J. \& Knook, D. L. (1989). Influence of copper deficiency on binding and uptake of apolipoprotein E-free high density lipoproteins (apo E-free HDL) by isolated rat liver parenchymal and Kupffer cells. FASEB Journal 3, A 1062.

Lci, K. Y., Rosenstein, F., Shi, F., Hassel, C. A., Carr, T. P. \& Zhang, J. (1988). Alterations in lipid composition and fluidity of liver plasma membranes in copper-deficient rats. Proceedings of the Society for Experimental Biology and Medicine 188, 335-341.

Morrison, W. R. \& Smith, L. M. (1960). Preparation of fatty acid methylesters and dimethylacetals from lipids with boron fluoride-methanol. Journal of Lipid Research 5, 600-608.

Schwarz, S. M., Ling, S., Hostetler, B., Draper, J. P. \& Watkins, J. B. (1984). Lipid composition and membrane fluidity in the small intestine of the developing rabbit. Gastroenterology 86, 1544-1551.

Shao, M. T. S. \& Lei, K. Y. (1980). Conversion of $\left[2-{ }^{14} \mathrm{C}\right]$ mevalonate into cholesterol, lanosterol and squalene in copper-deficient rats. Journal of Nutrition 110,859-867.

Spector, A. A. \& Yorek, M. A. (1985). Membrane lipid composition and cellular function. Journal of Lipid Research 26, 1015-1035.

Steck, T. L. (1974). The organization of proteins in the human red blood cell membrane. Journal of Cell Biology 62, $1-19$.

Storch, J. \& Schachter, D. (1984). Dietary induction of acyl chain desaturases alters the lipid composition and fluidity of rat hepatocyte plasma membranes. Biochemistry 23, 1165-1170.

Tahin, Q. S., Blum, M. \& Carafoli, E. (1981). The fatty acid composition of subcellular membranes of rat liver, heart and brain: diet induced modification. European Journal of Biochemistry 121, 5-13.

Tall, A. R. (1986). Plasma lipid transfer proteins. Journal of Lipid Research 27, 361-367.

Van Kuijk, F. J. G., Sevanian, A., Handelman, G. J. \& Dratz, E. A. (1987). A new role for phospholipase A, protection of membranes from lipid peroxidation damage. Trends in Biochemical Sciences 12, 31-34.

Wahle, K. W. J. \& Davies, N. T. (1975). Effects of copper deficiency in the rat on fatty acid composition of adipose tissue and desaturase activity of liver microsomes. British Journal of Nutrition 34, 105-112.

Weber, K. \& Osborn, M. (1969). The reliability of molecular weight determination by dodecyl sulphatepolyacrylamide gel electrophoresis. Journal of Biological Chemistry 244, 4406-4412.

Yount, N. Y., McNamara, D. J., Al-Othman, A. A. \& Lei, K. Y. (1990). The effect of copper deficiency on rat hepatic 3-hydroxy-3-methylglutaryl-coenzyme A reductase activity. Journal of Nutritional Biochemistry $\mathbf{1}$, 27.33.

Yount, N. Y., McNamara, D. J. \& Lei, K. Y. (1991). Incorporation of tritated water into sterols in copperdeficient rats. Biochimica et Biophysica Acta 1082, 79-84.

Zachariasse, K. A., Vaz, W. L. C., Sotomayor, C. \& Kuhnle, W. (1982). Investigation of human erythrocyte ghost membranes with intramolecular eximer probes. Biochimica et Biophysica Acta 688, 323-332. 